\title{
政
}

\section{ANSWER TO FOUR QUESTIONS ON THE LEGISLATIVE AND EXECUTIVE POWERS ${ }^{1}$}

Thomas Paine

\begin{abstract}
Thomas Paine, answering, supposedly, to Condorcet, about institutional definitions proposed to French Constitution, after the Revolution. He deals with themes as division and balance of powers; constitutional control; Legislature institutional organization; hereditary monarchy; constituent power and legislative power; constitutional reform.
\end{abstract}

Keywords: Division of powers. Balance of powers. Constituent Power. Legislative Power.

\section{Introduction $^{2}$}

The four questions goes around the division of powers and the balance of powers, central themes in any institutional design. Interestingly, the concern was with a Legislature stronger than the Executive, which can be understood by the circumstances in which the author was. How the powers should be organized, particularly the Legislative Power, was also an object of concern.

His proposal for a unicameral Legislature, but with a divided functioning, draws attention. In addition to the ingenuity of seeking to preserve the positive points of both unicameralism and bicameralism, his insight makes us denaturalize the most recurrent schemes in modernity which are bicameralism or unicameralism itself. Institutional design is a decision of men, not the imposition of nature.

It is noteworthy that Paine pays no attention to the Judiciary. In fact, it affirms the existence of the Legislative Power and the Executive Power. The Judiciary, as a result, would be an arm of the Executive.

Without giving details, Paine anticipates an important concern, which would attract much discussion on the part of constitutionalists - the control of constitutionality. For him, this control should happen automatically, by the Constitution itself. If the laws passed by the Legislature were not consistent with the foundations and principles of the Constitution, they should be

\footnotetext{
${ }^{1}$ It is impossible to determine the exact date of the composition of this document, but it is very likely that it was started in the spring of 1791 and completed some time during the following summer. It was later translated by Condorcet and published in the Chronique du Mots for June and July, 1792. The questions to which Paine replies were probably put to him by Condorcet, and related to the Constitution submitted by the French National Assembly.-Editor.

${ }^{2}$ Introduction written by the translator, Prof. Dr. André Rehbein Sathler, faculty of the MA in Legislative Affairs of the Brazilian Chamber of Deputies.
} 
ignored. This would be practiced, as indicated, by the Legislative's own self-restraint. Paine also highlights how the constitution should be able to be changed.

Another anticipation is the debate over the amount of government needed - which in modern terms could be translated as the discussion about the size of the state. Paine calls attention to an interesting question: people want less government for themselves, but more government for others. Very consistent with human nature - wanting the bonuses, but not the government's burden. Everyone subscribes to the social contract, but some clauses must be worth more to some than to everyone. The solution would lie between these two extremes.

From a government sustainability point of view, the author points to something important: good governance is not enough, a method is also needed to maintain it. Embryo of institutionalism, the idea also adds to the contempt that Paine had for the hereditary monarchy (which could even have experiences of good government, depending on the monarch at the time, but which was a regime destined to fail because it had no guarantee of maintaining this good government). Optimistic and living in the effervescence of two liberal revolutions, Thomas Paine leaves his hope of progress as regards the solutions to political issues: "Political questions are being so vastly illumined by the light of reason that the dread of man ever again plunging back into the foul night of ignorance is a dread which should be energetically discarded".

\section{Answer to four questions on the legislative and executive powers}

Four questions to which you do me the honor of requesting na JL answer have been sent to me in a letter by my friend $\mathrm{M}$ Laying aside the usual complimentary preliminaries, I purpose replying to them at once: for a man who regards the whole human race as his own family has little time for compliments or excuses.

It is obvious that the person who has laid these four propositions before Thomas Paine has done so with the expectation, or, at least, with the hope, that they may receive an affirmative reply. Indeed, this conclusion is easily gathered from the language he uses, which clearly implies that that austere Republican must give an affirmative reply if he is to hope for that grateful approval which is merited by every task that helps along the progress of human freedom.

Well, then, I, too, can truly assert that I am keenly interested in the felicity of humanity among all peoples and in all lands, and, therefore, as a fraternal and sympathetic worker, associated with you and with everyone who holds similar opinions, I will, with all possible brevity, reply to your questions, and also submit certain considerations which they have prompted. In the meantime, however, you must not for a moment imagine that I have any intention of discussing the agreement or non-agreement of our opinions in all cases; but, as we 
are both aiming at the same goal, I shall confine myself to the task of simply discussing with you the best means of reaching that goal.

After acknowledging that the foundation upon which the French Constitution rests is excellent, you point out its deficiencies in many particulars, and then you demand:

1. As there is a want of equilibrium between the legislative and executive powers, is not the latter exposed to the danger of being overbalanced by the former?

2. Is not the executive power too feeble to be able to force the people to obey the law and also too feeble to obtain the respect and confidence necessary to a stable government?

3. Is not a legislative body composed of a single chamber likely to be the victim of its own rash impulsiveness and unrestrained impetuosity?

4. Is not the administrative system organized in such an intricate fashion as to lead to anarchy of a permanent character?

I shall first consider these questions individually, and afterwards deal with them collectively. On the other hand, while I do not care to enter at present into any debate as to their supposed amelioration or curtailment, I intend to bring to your notice a scheme for their modification in such a way as not to interfere with the orderly course of government, should such modification be deemed essential.

As to your assertion that the foundation upon which the French Constitution rests is excellent, there can be no difference of opinion between us, for as that foundation is the rights of man, the principle is too obvious to admit of argument. The man who should venture to gainsay it would thereby establish his kinship to the fool who said in his heart there is no God.

\section{First question}

"As there is a want of equilibrium between the legislative and executive powers, is not the latter exposed to the danger of being overbalanced by the former?"

If the legislative and executive powers be regarded as springing from the same source, the nation, and as having as their object the nation's weal by such a distribution of its authority, it will be difficult to foresee any contingency in which one power could derive advantage from overbalancing the other, even if it were successful in doing so. If, on the other hand, these two powers be considered as not springing from the same source, and as, in fact, mutually hostile, 
the one contending for the rights of the nation, the other for the privileges of a class, then surely your question assumes an entirely different aspect: in that case, what we should have to dread would not be the imminence of a single calamity, but the ruin of the entire people.

It is impossible to judge from your words which of these views you adopt, and, in any case it would be far from easy to solve a problem whose solution depends on another problem, and, for that reason, I shall avail myself fully of the freedom which the indefinite nature of your question permits and shall make such observations as may naturally occur to me. Thus, while I may not solve the problem, I shall offer some suggestions which, perhaps, will conduce to its solution.

The baleful custom of misgovernment is so universal and the consequent sufferings of nations throughout the centuries have been so dreadful that the soul of man, helpless and blinded, has almost lost the faculty of vision; the result is that even at the present day his power of drawing a distinction between prismatic shades can hardly be said to be fully developed.

When we begin to use only such words as are fitted to express ideas simply and naturally, we see plainly that the powers of which governments are composed fall into two primary divisions: the law-making power and the executive or administrative power. There is nothing in government which really transcends these divisions.

There is, I fancy, a more exact comprehension among people generally of the character of legislative power than there is of that of executive power. By the former is understood the delegated power of enacting laws that are consistent with the foundation and principles of the constitution. Otherwise, the legislative power would be pure despotism, call it by what name you will.

But the meaning ordinarily assigned to the term, executive power, is indefinite, and, consequently, our conception of it is by no means so exact and plain as when we speak of legislative power. It is associated, some way or other, in our minds with the idea of arbitrary power, and thus a feeling of suspicion rather than of confidence is aroused. You see, then, the absolute necessity of an exact definition of these two powers and the difficulty of dealing with the questions they involve in the absence of such definition.

Now, if we suppose it possible for one of these powers to encroach on the province of the other, then, of course, we must also suppose that the ability to do so is as great on one side as on the other. In that case, it is my opinion that the nation will be safer when an elected legislature controls the executive than when a non-elected executive attempts to usurp the function of legislation.

But, putting aside these considerations, I confess my inability to perceive the correctness of the comparison of a government to a pair of scales. In what does it consist? The idea which a pair of scales calls up is that of opposition. The metaphor, I imagine, originated in England at a period when, owing to certain circumstances, it had a certain fitness.

After the Norman Conquest, that nation, despairing of ridding itself of its oppressors, 
devoted itself for centuries to the task of rinding a sort of counterpoise against their tyranny. For, with the advent of that conquest, arrived aristocracy, and the calamities with which the people had to contend were innumerable. Hence the nation threw its whole weight in the balance against royalty and aristocracy. This afterwards came to be called the balance of the nation poised against the balance of the court.

In a country, however, in which all the powers of the government spring from the same source, such a metaphor has no meaning. In such circumstances we cannot even conceive the possibility of two hostile governmental forces in opposition; instead of such a conception, there looms up before us one single edifice in which all is united and harmonious.

\section{Second question}

And now I come to the second question: "Is not the executive power too feeble to be able to force the people to obey the laws, and also too feeble to obtain the respect and confidence necessary to a stable government?"

If a first proposition is fundamentally wrong, all the propositions dependent on it must necessarily be also fallacious. In this connection, therefore, the question that naturally suggests itself is: What is meant by executive power? Should the answer be: the power of enforcing the laws, then the phrase relates to every court of justice bound to carry out the laws whenever their enforcement is resisted. It must always be the special object of the legislature to defend the executive under this aspect; for if respect for the law is enfeebled, the laws and those who enacted them will also be treated with contempt. Should, however, the opinion prevail that the executive has not power to compel obedience to the laws and that it cannot win respect and submission from the people, another question arises: Why has it been unable to do so?

Such a question involves the consideration of the executive power under another aspect, namely as the medium through which the laws are executed rather than as the executor. When the subject is regarded from this point of view, we are forced to dwell on that part of the Constitution styled the monarchy.

The primary significance of the term "monarch" implies the absolute power of a single individual. In fact the word is capable of no other interpretation. However sublime the principles of the Constitution may be, we must perceive here an evident contradiction between words and ideas. Now, such a contradiction always gives rise to suspicion, and, therefore, it will be well to consider how far such suspicion tends to hinder the proper execution of the laws.

Should the recollection of the characteristics of the power of monarchy in the past, and the ideas which that recollection suggests, be in any way connected with the present executive, all plans intended to invigorate the latter will serve only to augment suspicion and diminish 
confidence.

If it were a law of nature, or if God had issued a decree and revealed it to mankind, that, in accordance with His will, every successive custodian of authority should possess the same heart, a heart, too, incapable of guile, all suspicion and dread would vanish at once. But when we perceive that, from the mode in which nature acts, it is her apparent intention to reject the monarchical system, inasmuch as the monarchs on whom she bestows existence are sure to differ from one another both in person and disposition, one being wicked, another stupid, another insane, and another at once wicked, stupid and insane, it must surely be impossible for any reasonable person to believe any longer in such na absurdity as hereditary monarchy.

Should the French be as impervious to common sense as the English have been, such drowsy unconcern might be regarded as a state of felicity, and their thoughtlessness might be considered confidence; but confidence, to be permanent, must be based on reason.

\section{Third question}

We have now reached the third question: "Is not a legislative body composed of a single chamber likely to be the victim of its own rash impulsiveness and unrestrained impetuosity?"

This question can scarcely receive a positive answer at present because of its complexity and of the questions involved in its discussion. Still, I shall endeavor to communicate to you the thoughts that it suggests. When a constitution determines the limitations of authority and the principle to which the legislative body must yield obedience, it has already secured a most potent and effective check upon all abuses of authority.

Suppose, for example, a bill were introduced in one of the American legislatures, like the one which became law in an English Parliament under George I, lengthening the duration of that legislature, it never could be enacted as a law, because such a law would be a violation of the Constitution, which limits the power of the legislature.

Still, notwithstanding the limitations that restrain power in its several departments provided by the Constitution, much will always depend on the wisdom and discretion exhibited by the various legislatures themselves.

However skilfully a constitution may be framed, it is impossible to decide previously, when there are two chambers, how far they will act as a check upon each other. They may come to an agreement not to avail themselves of this power of mutual restraint, either for good or evil; still, if the Constitution makes provision for such restraint, the result is sure to be advantageous.

In my opinion, for which I shall adduce reasons, it would be well to separate the legislature into two bodies before the discussion of any subject commences. Such an arrangement is preferable to the formation of one body always, or to the establishment of two divided 
chambers.

With reference to the sort of separation suggested, more consideration should be given to human passions than even to reason. Because the object is conviction or persuasion, the influence exercised by such passions is of considerable importance, and a legislature composed of a single chamber is always exposed to the peril of deciding with precipitation; when it is divided, there will always be room for judicious reflection.

The utility of discussion is obvious, and occasionally a man of superior attainments will derive profit from the ideas of a person who is his inferior intellectually; if it be his purpose to put in practise some of the ideas to which he has listened, he should, as far as possible, avoid speaking himself.

My plan would be to divide a legislature, consisting, say, of a hundred representatives, into two equal sections. The first section would discuss some question, while the second section listened. Then the second section would take up the same question. Then, after each section had heard the arguments of the other, the debate would be closed, and the subject finally submitted to the decision of the entire legislature. At least, some plan should, in my judgment, be adopted that would obviate the inconveniences which at present hamper the proceedings of a single chamber, and that would yet not entail the evils inherent in the existence of two chambers. Some of those evils I now propose to lay before you.

First, it is contrary to common sense for one part of the legislature to have it in its power to decide a question while that question is being debated in another body, and while fresh light is being thrown on the discussion. In the second place, it often occurs that when a question is voted on in these separate chambers, the majority is controlled by the minority in a manner that is as repulsive as it is absurd.

Let it be assumed, for example, that each of the chambers has 50 members. Now we can easily imagine a case in which the members of one assembly are unanimous, while those of the other are divided on the question in the proportion of 26 to 24 . Here we have 26 outweighing 74 , or, in other words, three-fourths of the legislators compelled to submit to one-fourth.

On the other hand, if the legislature be divided in the way I have suggested, you gain all the advantages derived from separate debate without the evils which accompany the establishment of two chambers.

The two chambers which form the English Parliament need not be discussed here. As legislative bodies, they have no really distinctive individual character. Their ideas are entirely molded and colored by those of the Prime Minister in power. He waves over them his sleepcompelling wand, and they are at once plunged in the slumber of servitude.

Should we turn our eyes on the members of one of those chambers, profanely styled the House of Lords, 3 a designation that insults nature, we discover that nature has avenged herself by bereaving them of talento and virtue. The entire representation of England is indeed 
calculated to arouse compassion; still, when contrasted with the Lords, the Commons are comparatively respectable. So slight is the regard paid to that childish body that the people never make any inquiries as to its proceedings.

As an instance of its subjection to ministerial influence, I will mention that it gave the minister a majority of 90 after the debate on the war with Russia, whereas the House of Commons, which has double its number, gave him a majority of only 63. It has been well styled by Lord means master. Chesterfield, one of its members who was thoroughly acquainted with its composition, "the hospital for incurables." I am not at all in favor of two chambers which have each an arbitrary veto on the action of the other. There is nothing to prove that one body will exhibit more sagacity than the other, and to confide power to a body that lacks wisdom is to incur a peril rather than to provide a safeguard. As all human institutions have grown better with the progress of time, we have every reason to believe that with time also the representative system will grow better. This belief is strengthened by the fact that, just as it has encountered the greatest opposition, so it stands the best chance of at last attaining perfection.

\section{Fourth question}

We have now reached the fourth question: "Is not the administrative system organized in such an intricate fashion as to lead to anarchy of a permanent character?"

There has been great progress in the science of government, and particularly where the state has a wide extension. This consists in allowing the several parts of a country to manage its own domestic affairs. In this fashion not only can public and private affairs be carried on with greater ease, but the loss of time and the expense incident to centralization are avoided, as well as the errors entailed by such a legislative system.

From a general standpoint, I think the usefulness of the institution to which I have alluded is unquestionable; still, I must confess that I have not any special knowledge of its work in practise, for it has Always been my object to endeavor to throw light upon general principles rather than on their application to particular cases; because if the former be sound, the latter will be sound also. But, as the science of government isso far only in its childhood, I can but hope that, whatever system may be adopted, it will permit us to take advantage of the lessons of experience.

Although much study has been devoted to the science of government in all its manifestations, one subject closely connected with it has never received the full consideration it deserves; namely, how small is the measure of government that is actually required by man? 
This question is fully discussed in a work I am now writing; and, moreover, to deal adequately with it at present would transcend my limits. But I am strongly inclined to believe that very little government is necessary, and that the need of government above measure is one of those ideas from which it would be well to free ourselves as early as possible.

When I inquire of a person how much government does he require, the answer I get is that he requires very little. But let me ask the same individual what amount of government he judges to be required by others, and he replies: "Oh, a very large amount, indeed!" If I continue my inquiries, I receive pretty much the same answers, and so I infer that the amount actually needed lies between these two extremes: the lesser amount each considers required for himself and the larger amount he regards as needful for his neighbor. Government beyond measure has the effect of giving encouragement and birth to crimes that otherwise might never have come into being.

The governments of the past managed to stimulate enmity and suspicion in every direction between nations as well as between individuals, and in this fashion to perpetuate their miserable domination. The success of such a system is calculated to uproot the very foundations of society, and we still feel the effects of its corrupt putrescence. It follows that the moral nature of man must inevitably change, and that, when he is subjected to sounder principles of government, he will no longer be the suspicious creature he could not help being under the old systems.

Now that nations seem to incline more and more toward the principles of civilized government, they would appear also to have gained the possession of a new faculty.

The relations between the French and English nations have assumed quite a different character during the last couple of years, and we may hopefully look forward to a similar change between the individuals of these two nations. Still, the moral changes that affect nations or individuals produce their consequences far more rapidly when their tendency is evil than when it is beneficial. Suspicion may be spread without any trouble; it cannot be uprooted with anything like the same facility. If you try to eradicate it forcibly, you fail; but if you succeed in quietly undermining it, it will gradually pass away silently and noiselessly.

When we contemplate the condition of France under the old regime, we behold a government that depends for its existence upon suspicion, upon spies and detectives employed by the police authorities. There could be no confidence in social circles, where everyone was in the habit of suspecting his neighbors; the master was suspicious of his servants, neighbors of one another, the Government of everyone, and every one of the Government. It is natural, then, that the present Government should also be suspected. This suspicion is a relic from the past, a past which it would be fortunate if the nation could forget altogether. 
I shall now treat of the best methods for the improvement of the Constitution, whenever experience shows the necessity of such improvement, without disturbing the orderly course of government. The best method would be to add a clause to the Constitution determining the manner of such improvements. There are very different ideas upon this subject, and, for that reason, I propose discussing it in a special fashion.

Until the present moment, France has had no constitution; she is now about to form one and to choose a legislature. In these circumstances it is absolutely indispensable to draw a distinction between the position of the people in the act of delegating its power to those who will establish a constitution, and its subsequent position after delegating its power to a legislature elected in virtue of that constitution. Now, the Constitution and the laws are altogether different from the power of enacting laws to suit particular contingencies, conformable to the principles of the aforesaid Constitution. If the original power to establish a constitution were vested in successive legislatures as a hereditary possession, a constitution could have no real existence; the legislature would be endowed with despotic authority, and could, as in England, establish whatever kind of government it chose.

The present National Assembly, or, to be strictly accurate, the National Assembly of the Convention, has been compelled by circumstances to undertake legislative functions at the very time it was establishing a constitution. Thus, owing to the enormous amount of business it had to transact in uprooting some institutions, and constructing others, and making provision for absolute necessities, its attention was being constantly distracted. Apart from the particular business to which its energies were devoted, its work in the establishment of a constitution embraces two special objects: the one destructive, the other constructive. In regard to the first point it could not err: the ancient structure was based on na evil principle; in other words, on usurpation.

Having reduced the subject to its elements, I shall now consider the second question, which relates to construction. The sound basis upon which the new edifice is founded fully compensates the nation for all it has endured. But have the builders of the new edifice been too frugal or too liberal in the use they have made of the old materials ? Are all its part equally symmetrical ? Has experience proved that it is less or more symmetrical than was needful?

These are questions which experience alone can answer. All that wisdom can do at present is to see that no future improvement shall be obstructed. However, there are two subjects upon which everyone has the same opinion: the boldness of the enterprise and the perseverance that has marked its achievement. It was to be expected that passionate ardor and the dread of falling back under bad government should have led the framers of the Constitution to be content with a relative excellence in their fear of retrogression. In view of the fact, however, that a final settlement precludes amelioration, this determination would seem of rather dubious value. Political questions are being so vastly illumined by the light of reason that the dread of man ever 
again plunging back into the foul night of ignorance is a dread which should be energetically discarded.

In every land throughout the universe the tendency of the interest of the greatest number is in the direction of good rather than of evil, and the inevitable result must be to elevate the science of government to a height of perfection of which we have now no conception. To fetter ourselves would be folly; to fetter posterity would be usurpation; we must do nothing that impedes progress. If man had any rights over posterity, our rights would have been ruined long ago. If, instead of regarding the future, we turn our eyes on the past, we see clearly that we should have been reduced to a very low condition indeed, if our ancestors had succeeded in laying that yoke upon our shoulders which we would fain lay upon our posterity. Had they done so, we should never have accomplished what we are now engaged in accomplishing. The enjoyment of his rights does not suffice for man; he should also be secured in their exercise by the principles of social order.

If we wish to benefit our posterity politically, let us leave them liberty as a bequest, and, along with it, the encouragement of good example. Everything that deserves imitation is sure to be imitated. If our institutions are intrinsically admirable, posterity will assimilate them, and there will be no necessity for us to try to exercise our authority over our descendants. When an inheritance is bequeathed, it never contains a clause enjoining its acceptance on the heirs, for such a clause would be altogether ineffective. The heirs will accept it if they deem it worth accepting, reject it if they believe the contrary. The same is the case with regard to government. The rights of man belong as much to our descendants as they do to us. We should not, in our zeal for their prosperity, begin by slighting their abilities. Perhaps, their wisdom will be more profound than ours. It would be folly in us to assert a privilege to which we have not the slightest claim.

The power of self-amendment forms a very marked feature of the Constitution. Very probably, no constitution could be established in which defects would not appear in the course of time. The best way of dealing with such defects is to provide a method of correcting them as they arise. No constitution which has not such a corrective can be permanent. The Convention which established the Pennsylvanian Constitution, in 1776, under the presidency of Benjamin Franklin, had a clause decreeing that the Constitution should be revised every seven years by a convention, and that such additions and retrenchments as public opinion demanded should be discussed. The amendments proposed were, however, to be laid before the people for a considerable period before they were voted upon. Another convention changed this clause into another, embodying the right of the nation to alter or perfect the Constitution whenever she should deem it necessary. 
I should prefer to such a general declaration as the above the exercise of power which would not weaken the absolute right, while, by its frequent use, it would compel the Government to avoid overstepping the principles of the Constitution.

The Federal Government of the United States, established in 1787 by the Convention over which General Washington presided, has in its Constitution a clause that calls for every improvement needed in the future. But such improvement must be effected by the authority of the people and by the same agencies that established the Constitution. It is not enough to constitute a good government; it is equally indispensable to adopt such methods as may assure the permanency of a good government.

Indeed, no constitution that does not make provision for this purpose can be considered complete. We are taught by experience that it is exceedingly hard to effect reforms, and, therefore, we benefit posterity when we adopt such contrivances now as will insure their success.

Provided the general principles of a constitution are sound, it will always be so easy to achieve such lesser reforms as are required by experience that the nation will never be persuaded to permit abuses to be piled upon abuses. In my judgment, it would be well to begin the revision of the Constitution in seven years from the present date, for during that period sufficient time will be afforded to make the people acquainted with its faults and virtues. It is worthy of notice that a few of the most important articles of the Constitution are due to particular circumstances rather than to reflection.

As an instance, I shall mention the decree concerning the right of peace and war. The two years which the Assembly spent in establishing the Constitution were assuredly not sufficiently long a period for the discussion of all the important subjects naturally connected with it. For this reason, the time for the first revision should not be put off too long, as we can easily see that certain additions and amendments will be absolutely needed. For that matter, it is by no means unlikely that before then all the European systems of government will experience a change, and that quarrels among nations will be terminated by pacific methods and not by the ferocious horrors of war.

The revolution which is influencing governments at present from West to East is quicker in its effects than the movement which once spread from East to West. I fondly hope that the National Assembly may have the courage to call for a convention of the representatives of the various nations of Europe, which would adopt measures for the general welfare. The felicity which liberty insures us is transformed into virtue when we communicate its enjoyment to others.

I should have completed this letter, which I began five weeks ago, sooner but for a journey which I had to make. Since then, the progress of events in France has been rapid, because of the flight and arrest of Louis XVI. All these events stimulate the reasoning faculty. Man advances 
from idea to idea, from thought to thought, and all the time he is unaware of his marvelous progress. Those who fancy that the goal of its political knowledge has been attained by France will soon discover their mistake, and will be quickly outstripped unless they quicken their own paces. Not a day passes unaccompanied by a novelty. The human mind, long accustomed to struggle with kings as individuals, must now regard them as forming part of a system of government, and must conclude that monarchy is only a base political superstition which should not exist among an enlightened people. It is mental servitude that has rendered it sacred.

Suppose we draw a circle around a man, and address him thus: "You cannot step beyond this boundary, for, if you did, you would be swallowed up in an abyss." As long as the terror with which these words have inspired him continues, he will stay where he is. But if, by some lucky accident, he places one foot beyond the line, the other will come after it. 